\title{
A FENOMENOLOGIA dA RELIGIÃo EM HEIDEGGER À LUZ DOS CONCEITOS VIVÊNCIA E EXPERIÊNCIA
}

\author{
The Phenomenology of ReLigion on Heidegger in the Light of the \\ CONCEPTS OF LIVED EXPERIENCE AND EXPERIENCE
}

\author{
LA FENOMENOLOGÍA DE LA RELIGIÓN EN HEIDEGGER A LA LUZ DE LOS \\ CONCEPTOS VIVENCIA Y EXPERIENCIA
}

\author{
Luís Gabriel Provinciatto*
}

\begin{abstract}
RESUMO
Pensar uma fenomenologia da religião em Heidegger requer, a princípio, uma dupla atenção: primeiro, a experiência fática da vida é o ponto de partida da fenomenologia; segundo, a tal experiência se vincula à vivência do mundo circundante. Por isso, só é possível afirmar uma fenomenologia da religião em Heidegger enquanto fenomenologia da experiência religiosa. Disso decorrem três questões: qual o significado de experiência? Por que e como ela se vincula à vivência? O que vem a ser o religioso que caracteriza a experiência? Ao pôr essa problemática, este trabalho ${ }^{1}$ desenvolve a hipótese de que o religioso é compreendido como fenômeno, advindo, assim, como experiência de sentido, ou seja, como sentido de conteúdo, de referência e de realização.
\end{abstract}

Palavras-chave: Fenomenologia. Indicação formal. Intuição hermenêutica. Situação hermenêutica.

\begin{abstract}
In principle, thinking about the phenomenology of religion in Heidegger requires double attention: first, the phatic life experience is the starting point of phenomenology; second, this experience is linked to the lived experience of the surrounding world. Therefore, it is only possible to affirm a phenomenology of religion in Heidegger as a phenomenology of religious experience. This leads to three questions: what is the meaning of experience? Why and how is it linked to the lived experience? What is the religious that characterizes the experience? By addressing this problem, this paper develops the hypothesis that the religious is understood as a phenomenon, thus arising as an experience of meaning, that is, as a sense of content, relation and enactment.
\end{abstract}

Keywords: Phenomenology. Formal indication. Hermeneutic intuition. Hermeneutic situation.

\section{RESUMEN}

En principio, pensar una fenomenología de la religión en Heidegger requiere una doble atención: en primer lugar, la experiencia fáctica de la vida es el punto de partida de la fenomenología; en segundo lugar, dicha experiencia está vinculada a la experiencia del mundo circundante. Así, sólo

\footnotetext{
* Mestre em Ciências da Religião pela Pontifícia Universidade Católica de Campinas. Doutorando em Ciência da Religião pela Universidade Federal de Juiz de Fora, bolsista CAPES. Brasil. ORCID: 00oo-0003-05978641. E-mail: lgprovinciatto@hotmail.com.

${ }^{1} \mathrm{O}$ presente trabalho foi realizado com o apoio da Coordenação de Aperfeiçoamento de Pessoal de Nível Superior - Brasil (CAPES).
} 
es posible afirmar una fenomenología de la religión en Heidegger como una fenomenología de la experiencia religiosa. De ello se desprenden tres preguntas: ¿Cuál es el significado de experiencia? ¿Por qué y cómo ella está vinculada a la vivencia? ¿Qué es lo religioso que caracteriza la experiencia? Al plantear esta problemática, este artículo desarrolla la hipótesis de que lo religioso se entiende como un fenómeno, surgiendo, por lo tanto, como una experiencia de sentido, es decir, como un sentido de contenido, de referencia y de realización.

Palabras Clave: Fenomenología. Indicación formal. Intuición hermenéutica. Situación hermenéutica.

\section{INTRODUÇÃO}

Em O conceito de experiência em Hegel (escrito originalmente em 1942), Heidegger apresenta claramente aquilo que compreende como sendo o significado de experiência (Erfahrung), a partir de sua etimologia:

[Em alemão,] fahren [ir, orientando-se numa determinada direção] integra a palavra erfahren [experienciar], tendo nesta o sentido originário do mover[-se] para. Ao construir uma casa, o carpinteiro leva [fährt mit] a trave numa determinada direção. $\mathrm{O}$ ir [guiando] é um estender a mão para [Langen nach]: alguém [estende a mão] para fazer uma festa no rosto de alguém. $\mathrm{O}$ ir é um conduzir até chegar a: o pastor vai com o rebanho, conduzindoo ao monte. O experienciar é o conseguir chegar estendendo-se para e alcançando [auslangenderlangendes Gelanden]. O experienciar é um modo do estar-presente, quer dizer, do ser. (HEIDEGGER, 2002, p. 214-215, grifo do autor).

Esse significado define a experiência do fenômeno religioso? Sim. Pode-se simplesmente transpô-lo para as preleções heideggerianas do período inicial de Friburgo (1919-1923), nas quais aparece o termo experiência religiosa? Não. O que há entre o texto de 1942 e tais preleções é uma proximidade conceitual vista a partir da etimologia da palavra, o que permite ler o conceito de experiência em ambos os casos e alcançar seu significado no pensamento heideggeriano.

Ao dar alguma atenção às preleções, nota-se o uso tanto de experiência (Erfahrung), por exemplo, em experiência fática da vida (faktische Lebenserfahrung), quanto de vivência (Erlebnis), em vivência do mundo circundante (Umwelterlebnis), o que poderia gerar a primeira impressão de uma sinonímia entre ambos os termos. Contudo, afirmar a distinção entre experiência e vivência lançando mão dos binômios sujeito-objeto, subjetividade-objetividade, interioridade-exterioridade não é suficiente, pois, para Heidegger, esses binômios partem de um pressuposto teorético-epistemológico que não alcança a vida em seu acontecer originário: “[...] o sujeito da teoria do conhecimento não explica o significado metafísico do sentido do espírito, muito menos seu pleno conteúdo. [...] 
O espírito vivo [lebendig Geist] como tal é espírito essencialmente histórico no sentido mais amplo da palavra." (HEIDEGGER, 1978, p. 407, grifo do autor, tradução nossa). ${ }^{2}$ Dessa maneira, ao utilizar experiência e vivência, Heidegger não visa a elaboração de uma teoria epistemológica que justifique o uso do binômio sujeito-objeto, mas, ao invés disso, pretende alcançar o acontecer originário da vida como o que se põe de antemão à caracterização subjetiva-objetiva. Aquilo que é experienciado e trazido à palavra não é, a princípio, teoria, pois esta "[...] não é a atitude natural do pensamento, mas uma posição determinada, com implicações implícitas que ela mesma não reconhece.” (RODRÍGUEZ, 2019, p. 101, grifo do autor, tradução nossa). ${ }^{3}$ Vida fática e mundo circundante não são correlatos de sujeito, por um lado, e objeto, por outro.

A circunspecção em torno aos termos vivência e experiência, bem como à vida fática e ao mundo circundante se faz aqui necessária não para traçar uma linha divisória entre eles, mas para mostrar, em primeiro lugar, que ambos estão radicalmente vinculados e se implicam necessariamente. Só assim haverá condições de compreender o significado de experiência religiosa, bem como o de uma fenomenologia da religião em Heidegger, que, propondo-se a uma investigação fundamental, mostra que "[...] o que a fenomenologia procura ex-pôr é a experiência original." (ENES, 1971, p. 15). Em Heidegger, a fenomenologia se configura, em primeiro lugar, como ex-posição, ou seja, como o trazer à vista os fundamentos da possibilidade do acontecer originário da vida, como o "[...] ex-pôr o remanescente em subposição. Ora este fundamento su-posto coincide com o de que é alvo a hermenêutica. Hermeneuein quer dizer a ex-posição do su-porte que sus-tem a fala no seu mostrar-se." (ENES, 1971, p. 13, grifo do autor). A fenomenologia da religião, ou melhor, da experiência religiosa não pode prescindir, portanto, da hermenêutica, que, de fato, mostrase como a intencionalidade própria à experiência da vida fática e à vivência do mundo circundante, como veremos adiante.

\footnotetext{
2 [...] Das erkenntnistheoretische Subjekt deutet nicht den metaphysisch bedeutsamsten Sinn des Geistes, geschweige seine Vollgehalt. [...] Der lebendige Geist ist als solcher wesensmäßig historischer Geist in weitesten Sinne des Wortes.

3 [...] la teoría no es la actitud natural del pensamiento, sino una posición determinada, con implicaciones implícitas que ella misma no reconoce.
} 


\section{VIVÊNCIA COMO O ACONTECER ORIGINÁRIO DA VIDA}

Se o prefixo er-4, presente tanto em Er-lebnis quanto em Er-fahrung, indica o caráter originário do viver (leben), da vida (Leben) e do ir (fahren), Erlebnis designa, então, aquilo que é originário à vida, logo, esta vive se apropriando daquilo que se lhe origina e, a partir disso, particulariza-se. O viver é o âmbito originário da vida. Só é possível pensar a vivência a partir da vida. Contudo, vivencia-se o quê? Aqui “[...] estamos ante um abismo: ou nos precipitamos no nada, isto é, na objetividade [Sachlichkeit] absoluta, ou conseguimos dar o salto para outro mundo ou, mais exatamente, pela primeira vez no mundo em geral." (HEIDEGGER, 1999, p. 63, grifo do autor, tradução nossa).5 Já há aí um apontamento crítico: à questão sobre o que vivenciar, isto é, sobre o conteúdo da vivência, subjaz a afirmação de que se vivencia algo, ou seja, que há algo, donde o risco de, vivendo, a vida se precipitar na objetividade absoluta e, com isso, (re)cair no princípio teorético sujeito-objeto.

A possibilidade de um salto a outro mundo, passa, sobretudo, pela compreensão dos modos de realização da vida, ou seja, pelo como (Wie) da vivência, no sentido de posicionála em sua origem, antes do pressuposto teorético mencionado, pois “[...] um conhecimento como forma dessa vivência qua vivência significa uma formação teorética [...], uma racionalização do irracional, uma destruição ou paralisação da vida em um esquema de conceitos como meio e resultado da própria forma.” (HEIDEGGER, 1993b, p. 26, tradução nossa). 6 A exposição do como da vivência torna possível acessá-la em sua originariedade, pois o conteúdo da vivência não é assumido na condição de objeto, mas descrito em sua fenomenalidade, como aquilo que mostra-se-a-respeito-de-si-mesmo.

Esse movimento de incursão ao âmbito originário da vivência faz aparecer os seus três momentos fundamentais: (1) a vivência possui uma significação imediata, que, por sua vez, (2) acontece efetivamente porque quem vivencia é um eu-histórico, tornando possível

\footnotetext{
${ }_{4}$ Er- é, assim como ar- e ir-, um prefixo que tem sua origem em ur-, que, por sua vez, significa no começo, originário, mas também no final e, portanto, denota a origem de um evento e/ou a conquista de um fim. De acordo com o Dicionário dos Irmãos Grimm (1971), ur- carrega uma mobilidade: para cima (hinauf), para fora (hinaus), do fundo para o alto (von der Tiefe in die Höhe). O sentido de originário não pode ser entendido como um evento ocorrido no passado somente acessível pela historiografia (Historie) e, por isso, não coincide necessariamente com começo (Begin), tendo, antes, relação com início (Anfang) no sentido de que o que é originário apropria-se do passado, permanecendo presente e orientando o futuro. (GRIMM, J; GRIMM, W, 1971, colunas 2356-2359).

5 [...] Wir stehen na der methodischen Wegkreuzung, die über Leben oder Tod der Philosophie überhaupt entscheidet, an einem Abgrund: entweder ins Nichts, $d$. h. der absoluten Sachlichkeit, oder es gelingt der Sprung in eine andere Welt, oder genauer: überhaupt erst in die Welt.

${ }^{6}$ [...] Eine Erkenntnis als Formung dieses Erlebens qua Erleben bedeutet eine theoretische Gestaltung [...] eine Rationalisierung des Irrationalen, eine Zerstörung oder Stillstellung des Lebens im Schema der Begriffe als der Mittel und Ergebnisse des Formens selbst.
} 
(3) uma apropriação dessa significação (cf. HEIDEGGER, 1999, p. 63-76). Com isso, há uma estrita relação entre a significação e o eu-histórico. O modo de realização da vida, então, faz referência ao aspecto pré-teorético da vivência, logo, ao expor o como da vivência, não se estabelece previamente nenhum sujeito e nenhum objeto:

É verdade que não se trataria de uma coisificação e objetificação da vivência, de uma concepção contrária à vivência, se eu quisesse dizer que ela é algo como um "eu me comporto”. Decisivo, de fato, é que na simples observação não encontro algo assim como um "eu". O que vejo é vive-se [es lebt], e mais, que se vive direcionado para algo, e este "viver direcionado" é um "viver direcionado para algo interrogativamente", e esse algo ele mesmo tem o caráter da questionabilidade. (HEIDEGGER, 1999, p. 66, tradução nossa).7

Disso decorre a questão há algo? (gibt es etwas?). O que aí importa não é a pergunta em si, mas o que se pretende com ela, ou melhor, a partir dela, a saber: mostrar como a vivência de tal pergunta já parte, necessariamente, de aspectos prévios à própria pergunta $\mathrm{e}$ que fazem que ela faça algum sentido. Daí o exemplo da cátedra apresentado por Heidegger (1999, p. 70-73): não se a vê, a princípio, como madeira, caixote, cor e tudo o mais; a cátedra é vista, de chofre, enquanto tal, isto é, em sua significação imediata. O que, então, se extrai da vivência da pergunta há algo? é a constatação de que o mundo circundante, no qual se vive cotidianamente, não oferece objetos pura e simplesmente. Logo, a vivência da pergunta não coincide com a do mundo circundante, que, por sua vez, não apresenta as coisas em seu aspecto objetivo, mas em seu caráter significativo. Heidegger denomina esse dar a ver as coisas em sua significação, ou melhor, em sua significatividade, por meio de um neologismo: o vir-a-ser mundo (welten), ou também fazer-se mundo, noutra tradução possível.

O viver direcionado para algo mostra que a vivência do mundo circundante não é mediada conceitualmente, pois “[...] vivendo em um mundo circundante, encontro-me rodeado sempre e em qualquer lugar por significados, tudo é mundano, 'faz-se mundo' [es weltet], o que não coincide com ‘vale' [es wertet].” (HEIDEGGER, 1999, p. 73, grifo do autor, tradução nossa). ${ }^{8}$ Desse modo, o fazer-se mundo diz respeito à vivência da significação de maneira imediata, o que aponta para a intuição hermenêutica enquanto modo fundamental da vivência, afirmando, com isso, a antecedência da situação hermenêutica ao binômio

\footnotetext{
7 Zwar wäre es noch keine Verdinglichung und Versachlichung des Erlebnisses, eine ihm widerstrebende Auffassung, wenn ich sagen wollte, es liege so etwas darin wie „ich verhalte mich“. Entscheidend ist: Das schlichte Hinsehen findet nicht so etwas wie ein „Ich“. Ich sehe: Es lebt, und weiter, es lebt auf etwas hin, und dieses „Leben auf hin" ist ein ,fragend Leben auf etwas hin“, und das Etwas selbst steht im Charakter der Fraglichkeit.

8 [...] In einer Umwelt lebend, bedeutet es mir überall und immer, es ist alles welthaft, „es weltet“, was nicht zusammenfällt mit dem „es wertet“.
} 
sujeito-objeto. Como há uma intuição hermenêutica, a vivência não pode ser caracterizada como coisa, tampouco como objeto. O que vem à palavra, então, não é, a princípio, o conceito de algo, mas o sentido daquilo que aí se mostrou enquanto tal e foi desse ou daquele modo vivenciado. Como não há um binômio pré definidor e que cinde sujeito cognoscente, por um lado, e objeto conhecido, por outro, pode-se afirmar que há uma identificação entre o quem e o como da vivência, isto é, entre a vida, ou melhor, o viver (leben) e o vir-a-ser mundo (welten). Disso decorre a afirmação de que a vivência, a priori, não determina uma subjetividade, tampouco uma objetualidade.

A Carta aos Gálatas traz um relato interessante a esse respeito. Nela Paulo afirma: “[...] já não sou eu quem vivo, mas é Cristo que vive em mim [...]” (Gl 2, 20). O que há aí é justamente a identificação entre o vivenciado - a fé em Cristo, que, nesses termos, faz-se mundo - e quem vivencia - Paulo -, que, vivenciando, não se encontra como sujeito, pois se identifica a Cristo, o sentido do viver. A fé se manifesta aí como fenômeno. Esse é um dos pontos decisivos para a leitura feita por Heidegger a respeito do cristianismo, de modo que “[...] para ser cristão não basta ter uma opinião sobre a vida; [ser cristão] é um modo de se comportar, um tipo de vida fática.” (VEDDER, 2006, p. 53, tradução nossa). 9 Ser cristão, portanto, diz respeito a como (Wie) se vive, o que faz que o discurso paulino não seja uma especulação teórica sobre a fé, da qual ele próprio não faria parte: “[...] o destino de Paulo está unido ao da comunidade. A partir dessa 'situação' de solidariedade, ele fala para a comunidade. Seu próprio lugar é parte de sua fala.” (VEDDER, 2006, p. 53, tradução nossa). ${ }^{10}$ Como o ponto de partida da vivência é pré-teorético, o vivenciado é fenômeno e o que vem à palavra é o sentido já compreendido desde uma determinada disposição afetiva, conforme descrito posteriormente em Ser e tempo (cf. HEIDEGGER, 1967, p. 134-167). O que a palavra manifesta é o fenômeno em seu mostrar-se-a-respeito-de-si-mesmo.

A vivência também possui caráter histórico, pois é, a cada vez, “[...] minha vivência, isto é, a vivência que se apresenta aqui, em mim, e que eu vivencio agora." (FERNANDES, 2010, p. 35, grifo do autor). Esse agora não é o das coisas, não diz respeito a uma temporalidade cronológica, mas tão somente ao agora originário, ao agora propício, ao instante (Augenblick) que, enquanto modo da vida fática, “[...] somente poderá ser determinado em seu caráter ontológico quando se tiver feito visível de modo explícito o

9 [...] for being a Christian is not merely having an opinion about life, according to Heidegger; it is a way of behaving, a type of factical life.

${ }^{10}[. .$.$] Paul's destiny is united with the destiny of the community. From this "situation" of solidarity, he speaks$ to the community. His own place is part of his speaking. 
fenômeno fundamental da facticidade: 'a temporalidade' (que não é uma categoria, mas um existencial)." (HEIDEGGER, 2013, p. 39, grifo do autor). Esse caráter originário do agora também está presente nas cartas paulinas: o fenômeno da $\pi \alpha \rho o v \sigma i \alpha$ - a segunda vinda de Cristo -, que, enquanto tal, não possui momento determinado para acontecer, podendo, na verdade, acontecer a qualquer momento. Ela, sem dúvida, indica um acontecimento vindouro, mas que não está objetivamente disponível antecipadamente para ser esperado,

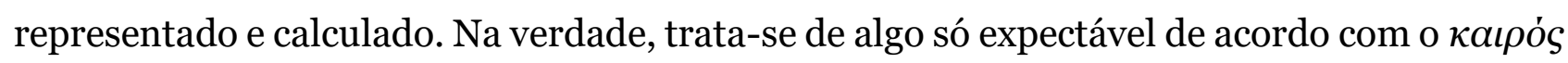
que o rege e não propriamente de acordo com a mensurabilidade proporcionada pelo

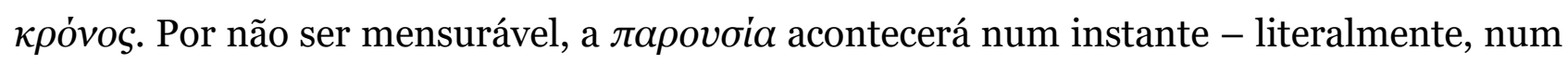
piscar de olhos (Augenblick) - tal como descrito por Paulo na Primeira Carta aos Tessalonicenses: “[...] no tocante ao tempo e ao prazo, meus irmãos, é escusado escrevervos, porque vós sabeis, perfeitamente, que o Dia do Senhor virá como ladrão noturno." (1Ts $5,1-2)$. Orientar a vida a partir desse evento futuro, certo, por um lado, e incerto, por outro, significa orientá-la desde uma fragilidade que só pode ser compreendida a partir daquilo que se é, ou seja, sendo aquilo que se é.

Todavia, viver com vistas à $\pi \alpha \rho o v \sigma i \alpha$ não é recusar o tempo cronológico. Trata-se, pois, de assumir a condição de que já sempre se é a cada vez desde outra perspectiva, a do $\dot{\omega} \varsigma \mu \dot{\eta}:$ :[...] esse $\dot{\omega} \zeta$ significa positivamente um novo sentido que vem ao encontro. O $\mu \dot{\eta}$ se refere ao nexo de realização da vida cristã.” (HEIDEGGER, 1995, p. 120, tradução nossa).11 Em outras palavras, a vida cristã propriamente dita não se deixa guiar pelos conteúdos mais imediatos do mundo circundante, porém, não propõe algo como uma fuga desse mundo no qual se encontra lançada: "[...] mesmo permanecendo totalmente imerso nos conteúdos próprios de sua condição histórica, o cristão permanece na fé, espera pelo retorno do Senhor." (VATTIMO, 2004, p. 165). O cristão vive o já de sua existência na condição de ainda não: por meio da morte e ressurreição de Cristo, ele já está salvo, mas isso ainda não se realizou em plenitude, pois, ao evento da cruz, deve se suceder a $\pi \alpha \rho$ ov $\sigma i \alpha$, que é, de fato, o que orienta o modo de realização da vida cristã.

Nesse sentido, as cartas paulinas mostram a vida cristã em seu viver mais próprio. Nelas, a fé é o sentido encontrado: “[...] a experiência religiosa da vida me prende no mais íntimo de mim, a experiência aparece na proximidade imediata de meu eu próprio, eu sou, por assim dizer, esta experiência.” (HEIDEGGER, 1993a, p. 208, grifo do autor, tradução

\footnotetext{
${ }^{11}[. .$.$] Dies \dot{\omega}$ bedeutet positiv einen neuen Sinn, des dazukommt. Das $\mu \eta \dot{~ b e t r i f f t ~ d e n ~ V o l l z u g s z u s a m m e n h a n g ~}$ des christlichen Lebens.
} 
nossa). ${ }^{12} \mathrm{O}$ aspecto temporal-histórico vincula vivência e facticidade. Por isso, a vivência não é apreendida como um processo (Vorgang), que corresponde “[...] a um procedimento objetivante que contempla as vivências de um modo neutro e distante, isto é, desvinculadas do eu fático que vive, afastadas do eu-histórico que experiencia, separadas artificialmente do eu-histórico." (ESCUDERO, 2009, p. 188, tradução nossa).13 Apreendê-la como processo conduz à sua desvivificação (Entlebung). Há a possibilidade de apreendê-la não como processo justamente porque a vida é histórica por excelência, acontecendo tanto em um agora quanto em um aí, que, juntos, dão orientação à vivência, logo, ao sentido por ela encontrado: "[...] a interpretação é o que dá ao 'aí' do ser-aí fático o caráter de um estar orientado, o que delimita muito bem seu possível modo de ver e o alcance de sua visão.” (HEIDEGGER, 2013, p. 40).

O viver direcionado para algo, portanto, nunca é isento de pressupostos, nunca neutro. Ele sempre parte de uma situação determinada. Tanto o agora quanto o aí remetem ao âmbito originário da vida e, dessa maneira, rompem com o pressuposto teorético acima mencionado. $\mathrm{O}$ aspecto histórico só pode ser concebido desde a temporalidade e diz respeito a um acontecer (geschehen) que dá origem à história (Geschichte), ao “[...] acontecer mesmo da história, ao movimento de gestação histórica ao qual está submetida qualquer parte da existência humana." (ESCUDERO, 2009, p. 100, tradução nossa). ${ }^{14}$ Por isso, a história é um elemento estruturante da vida, fazendo referência à "[...] finitude inigualável de cada eu singular que vive e encarna toda vivência do mundo circundante." (CÁCERES, 2014, p. 228, tradução nossa). 15

Antes de ser um processo, a vivência é um acontecimento. O eu-histórico acontece e se apropria do sentido que lhe advém mundanamente. Assim, não há nenhuma imposição de sentido, mas tão somente a sua descoberta, não porque ele seja algo perene e esteja anexado ao fenômeno tal qual um selo, mas porque ele se origina, porque, no limite, faz-se mundo: “[...] a vivência não se dá para mim como uma coisa que eu coloco aí, como objeto, senão que eu mesmo me aproprio [er-eigne] dela, e ela mesma se apropria [es er-eignet sich]

${ }_{12}$ [...] Religiöse Lebenserfahrung erfasst mich in meinem innersten Selbst, die Erfahrung tritt in die unmittelbare Nähe meines Selbst, ich bin sozusagen diese Erfahrung.

${ }_{13}[. .$.$] a un procedimiento objetivante que contempla las vivencias de una forma neutra y$ distante, esto es, desvinculadas del yo fático que vive, desgajadas del yo histórico que experimenta, separadas artificialmente del yo histórico.

14 [...] acontecer mismo de la historia, al proceso de gestación histórica al que está sometida cualquier parcela de la existencia humana.

15 [...] la finitud inigualable de cada yo singular que vive y encarna toda vivencia circu-mundana. 
segundo sua essência.” (HEIDEGGER, 1999, p. 75, tradução nossa). ${ }^{16}$ Atenção seja dada ao prefixo er-, marcado por Heidegger no início do verbo ereignen (apropriar-se), tal como em Er-lebnis e Er-fahrung, indicando o modo originário de um acontecimento (Ereignis) ${ }^{17}$. A apropriação do sentido vincula vida e mundo, de modo que aquela se encontra sempre imersa nas significações advindas mundanamente.

Isso faz perceber o radical vínculo entre os três pontos fundamentais da vivência. $\mathrm{O}$ caráter significativo do mundo, ao acontecer, sempre o faz a um eu-histórico que, por sua vez, se apropria dessa significação; “[...] as vivências são acontecimentos [Er-eignisse], na medida em que vivem a partir do que lhes são próprios [Eigenen] e é só assim que a vida vive.” (HEIDEGGER, 1999, p. 75, tradução nossa). ${ }^{18}$ Note-se: não é possível desvincular acontecimento e apropriação, o que inviabiliza a apreensão da vivência como processo, tornando-a, de fato, histórica. O que a individualiza é seu caráter histórico, donde a afirmação de um eu-histórico, que como “[...] um ser que se constrói numa situação dada, [...] está presente na mais elementar das percepções e para quem as coisas aparecem desta ou daquela maneira.” (RODRÍGUEZ, 2019, p. 37, tradução nossa).19 A vida, em seu caráter originário, ou seja, em seu viver, é um acontecimento histórico-apropriativo. A singularização da vida é fática, acontecendo, de fato, como o ir orientando-se em uma determinada direção, ou seja, como experiência. Como “[...] a vida se dá, na minha experiência, de modo muito mais imediato, próximo, originário, em todas e em cada uma das vivências” (FERNANDES, 2010, p. 40, grifo do autor), então, a experiência fática da vida (faktische Lebenserfahrung) é um experienciar direcionado a partir da vivência do mundo circundante (Umwelterlebnis), na qual experiência e ser se identificam.

\footnotetext{
${ }^{16}$ [...] Das Er-leben geht nicht vor mir vorbei, wie eine Sache, die ich hinstelle, als Objekt, sondern ich selbst er-eigne es mir, und es er-eignet sich seinem Wesen nach.

${ }_{17}^{17}$ Atenção quanto ao uso do termo Ereignis, utilizado por Heidegger já nas preleções de 1919, mas num sentido específico e, por isso, distinto daquele que irá marcar outro período de seu pensamento, expressado, sobretudo, na obra Contribuições à filosofia: do acontecimento-apropriador (1936-1938). Nas preleções, Ereignis é utilizado em relação direta com Erlebnis, que, por sua vez, encontra seu fundamento na intuição hermenêutica, o ponto de partida da filosofia como ciência originária pré-teórica. Por isso, acontecimento (Ereignis) é o contraposto imediato a processo (Vorgang), significando o acontecimento manifestativo do fenômeno em seu caráter mais próprio. Ou seja, ao mesmo tempo que é um acontecimento, Ereignis designa um movimento de apropriação do sentido, advindo mundanamente. Tal apropriação capta o sentido sem objetivá-lo, ou seja, sem torná-lo, a princípio, em conceito estático, em definição. Dessa maneira, Ereignis, nas preleções de 1919, cumpre uma função muito importante para a afirmação da filosofia como ciência originária pré-teórica, logo, para o desenvolvimento de uma hermenêutica fenomenológica da facticidade.

18 [...] Die Erlebnisse sind Er-eignisse, insofern sie aus dem Eigenen leben und Leben nur so lebt.

19 [...] Un ser que se hace em una situación dada [...]. Es este yo histórico el que está presente en la más elemental de las percepciones y para quien las cosas aparecen de esta u otra manera.
} 


\section{AFINAL, POR QUE SE DIZ FÁTICA TAL EXPERIÊNCIA?}

Erfahrung não designa a mera experiência: trata-se, antes, de um lançar-se decidido e decisivo ao encontro daquilo que se dá mundanamente em sua originariedade. E mais: trata-se de um lançar-se sobre a própria vida. Assim, “[...] o existir fático determina um modo de compreensão da existência que já se dá no interior e a partir de si mesma, de tal forma que esta nunca pode ser contemplada 'de fora', como um objeto perante um sujeito." (SARAMAGO, 2008, p. 29). Há aqui eminente, embora não evidente, relação entre vivência e experiência: tanto uma quanto outra, justamente por escaparem à distinção sujeito-objeto, mostram que "[...] o que primeiramente deve ser evitado é o esquema: que há sujeitos $e$ objetos.” (HEIDEGGER, 2013, p. 87, grifo do autor). Daí a antecedência do eu-histórico em relação a qualquer subjetividade. Não é possível identificar ser-aí (Dasein) e sujeito. De fato, não se trata somente de uma mudança terminológica, substituindo um pelo outro. Trata-se, pois, de uma mudança principial - e existencial, na verdade -, uma vez que ser-aí abarca a situação hermenêutica em que o eu-histórico se encontra a todo momento, a saber, na posição de compreensão da existência que é a sua, recebendo a orientação, para tanto, senão do mundo, que, enquanto tal, é o horizonte ao qual o ser-aí está direcionado. Portanto, o caráter fático diz respeito a um modo sempre já levado a cabo da experiência do mundo circundante. A experiência da vida só é possível faticamente.

Ser-aí é vida fática. Isso porque esta é o solo mais próprio e originário daquele, de maneira que “[...] o conceito de facticidade: nosso ser-aí próprio em cada caso, em princípio não envolve na determinação de 'próprio' [eigen], 'apropriação' [Aneignung], 'apropriado' [angeeignet] nada em si da ideia de 'eu', pessoa, egoidade, centro de atos.” (HEIDEGGER, 2013, p. 37, grifo do autor). Ou seja, ser-aí não é sujeito. E não o é porque indica a facticidade da existência, guardando, pois, uma relação direta com o significado de experiência enquanto um viver direcionado. Numa palavra: ser-aí remete ao ser e ao viver direcionado pelo que mundana e imediatamente advém em sua significação. Logo, ser-aí remete ao vira-ser do mundo enquanto tal.

O experienciado na experiência advém ao ser-aí daquilo que ele vivencia, que outra coisa não é senão o mundo enquanto sentido. A experiência fática da vida também tem um aspecto pré-teorético, portanto. O ser-aí que experiencia não deixa de ser histórico em hipótese alguma. Colocar o esquema sujeito-objeto como ponto fundacional do experienciar seria retirar da vida fática todo o caráter de viver orientado: “[...] estar livre de perspectiva = ser sujeito viciado. A configuração da perspectiva é o primeiro no ser.” (HEIDEGGER, 
2013, p. 88). A intuição hermenêutica garante, justamente, a existência do ser-aí como fática, logo, como acontecimento mundano, histórico, significativo e apropriativo, donde a conclusão de que a vivência do mundo circundante (Umwelterlebnis) e a experiência fática da vida (faktische Lebenserfahrung) guardam uma relação necessária, implicando-se mutuamente.

O acontecimento do sentido marca a apropriação da vida em sua facticidade, logo, marca a identificação entre ser e experiência. O viver orientado da vida fática requer, então, a apropriação da própria situação hermenêutica:

[...] liberdade de perspectiva, se esta expressão deve significar algo, não é outra coisa que a explícita apropriação da posição do olhar. Esta posição é ela mesma algo histórico, ou seja, inseparável do ser-aí (a responsabilidade com que o ser-aí está consigo mesmo, responde por si mesmo), ninguém é em si quimérico e fora do tempo. (HEIDEGGER, 2013, p. 89, grifo do autor).

Como experiência não significa “[...] 'tomar conhecimento', mas o confrontar-se com as formas do que é experienciado, o afirmar-se de tais formas [...]” (HEIDEGGER, 1995, p. 9, tradução nossa), ${ }^{20}$ o que é experienciado não funciona tal qual um objeto. Seu caráter fático tampouco é algum pressuposto da teoria do conhecimento: “[...] ele deve ser compreendido apenas através do conceito de 'histórico”". (HEIDEGGER, 1995, p. 9, tradução nossa). ${ }^{21}$ Se aquilo que é experienciado é a vida, então ela não pode ser um objeto: “[...] denominamos o experienciado - o vivido - como 'mundo', não como 'objeto'. 'Mundo' é algo em que se pode viver (em um objeto não é possível viver).” (HEIDEGGER, 1995, p. 11, grifo do autor, tradução nossa). ${ }^{22}$ A fundamental relação entre vida fática e mundo se evidencia, pois, a partir da caracterização formal de mundo:

O mundo pode se articular formalmente como mundo circundante [Umwelt] (Milieu), como aquilo que nos vem ao encontro, ao qual não apenas pertencem coisas materiais, mas também objetualidades ideais, ciências, artes, etc. Nesse mundo circundante está também o mundo compartilhado [Mitwelt], isto é, outros homens em uma caracterização fática bem determinada: como estudante, docente, parente, superior, etc. - não como exemplares do gênero homo sapiens das ciências naturais e assim por diante. Finalmente, na experiência fática da vida está também o eu mesmo [Ich-Selbst], o mundo próprio [Selbstwelt]. (HEIDEGGER, 1995, p. 11, grifo do autor, tradução nossa). ${ }^{23}$

20 [...] Erfahren“ heißt nicht „Zur Kenntnis nehmen“, sondern das Sich-Auseinander-Setzen mit, das SichBehaupten der Gestalten des Erfahrenen [...]

${ }^{21}[. .$.$] Es wird nur vom Begriff des „Historischen“ her verständlich.$

22 [...] So bezeichnen wir das, was erfahren wird - das Erlebte -, als „Welt“, nicht als „Objekt“. „Welt“ ist etwas, worin man leben kann (in einem Objekt kann man nicht leben).

23 Die Welt kann man formal artikulieren als Umwelt (Milieu), als das, was uns begegnet, wozu nicht nur materielle Dinge, sondern auch ideale Gegenständlichkeit, Wissenschaften, Kunst etc. gehören. In dieser 
A vida se origina mundanamente e, por isso, é fática por excelência: “[...] o fático, assumido pelo conhecimento, não possui objetos, mas apenas caráter de significância que livremente pode tornar-se um conjunto de objetos conformados." (HEIDEGGER, 1995, p. 14, tradução nossa). ${ }^{24}$ Assim, a experiência fática da vida é experiência de sentido, que, por sua vez, não é nada objetivo. Note-se: o aspecto não objetivo da experiência fática da vida coloca-a numa posição anterior à teoria do conhecimento, portanto, antes do binômio sujeito-objeto. O vir-a-ser mundo (welten) nada mais é do que o acontecimento do sentido: “[...] tudo o que é experienciado na experiência fática da vida traz o caráter de significatividade [Bedeutsamkeit].” (HEIDEGGER, 1995, p. 13, grifo do autor, tradução nossa). ${ }^{25} \mathrm{O}$ sentido de ser do ser-aí, porque fático, está vinculado ao mundo como aquilo para e desde o qual o ser-aí se orienta. Assim, a vivência do mundo circundante só é possível enquanto experiência fática da vida. De fato, o sentido de ser do ser-aí é originário porque fático, ou seja, mundano, histórico, significativo e apropriativo.

Vincular mundo e sentido de ser não é afirmar somente que não existe experiência sem mundo, mas que não existe possibilidade de ser sem mundo:

Eu mesmo, em momento algum, experiencio meu eu separadamente, mas sou e estou sempre preso ao mundo circundante. Esse autoexperienciar-se [Sich-Selbst-Erfahren] não é uma "reflexão" teorética, não é uma "percepção interior" entre outras, mas experiência do mundo próprio, porque o experienciar mesmo tem um caráter mundano, tem uma acentuada significatividade, de modo que, faticamente, a própria experiência do mundo próprio não é mais retirada do mundo circundante. (HEIDEGGER, 1995, p. 13, grifo do autor, tradução nossa). ${ }^{26}$

A experiência fática da vida traz fundamentalmente um direcionamento para o mundo próprio. Como este é co-formado pelo mundo circundante e pelo mundo compartilhado, o direcionamento ao mundo próprio não designa um acontecimento isolado, como algo apartado e, por isso, “[...] a própria experiência do mundo próprio não é mais

Umwelt steht auch die Mitwelt, $d . h$. andere Menschen in einer ganz bestimmten faktischen Charakterisierung: als Student, Dozent, als Verwandte, Vorgesetzte etc. - nicht als Exemplare der naturwissenschaftlichen Gattung homo sapiens u. ä. Endlich steht auch das Ich-Selbst, die Selbstwelt, in der faktischen Lebenserfahrung.

24 [...] Das Faktische, von dem Kenntnis genommen wird, hat nicht Objekts-, sondern nur Bedeutsamkeitscharakter, der sich freilich zu einem ausgeformten Objektszusammenhang auswachsen kann.

25 [...] Alles, was in der faktischen Lebenserfahrung erfahren wird, trägt den Charakter der Bedeutsamkeit.

${ }^{26}$ Ich selbst erfahre nicht einmal mein Ich in Abgesetztheit, sondern hin dabei immer der Umwelt verhaftet. Dies Sich-Selbst-Erfahren ist nicht theoretische „Reflexion“, ist nicht „innere Wahrnehmung “ $u$. ̈̈., sondern selbstweltliche Erfahrung, weil das Erfahren selbst einen weltlichen Charakter hat, bedeutsamkeitsbetont ist, so zwar, daß die eigene erfahrene Selbstwelt faktisch gar nicht mehr von der Umwelt abgehoben ist. 
retirada do mundo circundante." (HEIDEGGER, 1995, p. 13, tradução nossa). ${ }^{27}$ A orientação em direção ao mundo próprio ainda dá à vida fática um caráter autossuficiente, de modo que ela não se orienta única e exclusivamente pelo mundo circundante, mas também desde o mundo compartilhado e de seu mundo próprio ${ }^{28}$. Não se trata, pois, de negar a vivência do mundo circundante, mas tampouco de dar-lhe a primazia. Esse é o ponto marcante da distinção terminológica entre vivência do mundo circundante (Umwelterlebnis) e experiência fática da vida (faktische Lebenserfahrung): esta assume a vivência do mundo circundante desde a perspectiva hermenêutica que lhe é própria, desde a acentuação decisiva ao mundo próprio, bem como da necessária co-manifestação de mundo próprio, compartilhado e circundante, que não são três regiões isoladas, pois cada um desses aspectos é co-formado pelo outro.

Como a experiência fática da vida se orienta pela co-manifestação de mundo próprio, circundante e compartilhado, a vida fática possui um caráter autossuficiente, ou seja, ela "[...] não precisa estruturalmente sair de si mesma (livrar-se de si mesma) para realizar suas genuínas tendências." (HEIDEGGER, 1993a, p. 31, grifo do autor, tradução nossa). ${ }^{29}$ Em outras palavras: ela não se orienta única e exclusivamente pelo mundo circundante, mas também pelo seu mundo próprio e pelo mundo compartilhado, fazendo com que o sentido de ser seja alcançado a partir dessa co-manifestação. No limite, a vida fática não precisa recorrer a nada que lhe é radicalmente estranho para sustentar o sentido desvelado: "[...] a autossuficiência é uma direção motivacional característica da vida em si, a saber, aquela

27 [...] Die eigene erfahrene Selbstwelt faktisch gar nicht mehr von der Umwelt abgehoben ist.

${ }^{28}$ A acentuação ao mundo próprio não é uma casualidade. O paradigma histórico que a marca é o advento do cristianismo: através dele "[...] o mundo próprio como tal entra na vida e é vivido enquanto tal.". (HEIDEGGER, 1993a, p. 61, tradução nossa). [Die Selbstwelt als solche tritt ins Leben und wird als solche gelebt]. O cristianismo surge como um nexo totalmente novo de acontecimento da vida. Trata-se, pois, de um novo modo de realização da vida que, na verdade, antecede todo conhecimento objetivo. Nesse sentido, a guinada em direção ao mundo próprio não é egóica, pois não pressupõe nenhum conhecimento objetivo de si. E mais: "[...] o mundo próprio não tem esta particular tendência funcional só no caso de personalidades significativas, mas toda vida anímica vive de algum modo centrada em um si mesmo - se bem que de forma não destacada." (HEIDEGGER, 1993a, p. 206, grifo do autor, tradução nossa). [Nicht nur bei bedeutenden Persönlichkeiten hat die Selbstwelt diese besondere funktionale Tendenz, sondern jedes seelische Leben lebt in irgendeiner Art zentriert in einem Selbst - wenn auch in unabgehobener Weise]. A guinada em direção ao mundo próprio é um dos pontos que torna possível compreender, por exemplo, a importância de Agostinho e do Livro $X$ das Confissões no pensamento heideggeriano, conforme apresentamos em outro trabalho (PROVINCIATTO, 2020). Aí o mundo próprio traz consigo tanto o mundo circundante e o mundo compartilhado quanto o caráter significativo e autossuficiente da vida fática, de modo que, ao centrar-se sobre o Livro $X$ das Confissões, Heidegger evidencia que "[...] o que Agostinho relata tem internalizado um sentido: o da imanentização que marca outro nexo não dual entre imanência e transcendência sem negar esta; a transcendência é o segredo aberto da imanência." (FLÓREZ, 2003, p. 65, tradução nossa). [Lo que Agustín relata tiene internalizado un sentido: el de la inmanentización que marca otro nexo no dual entre inmanencia y trascendencia sin negar ésta; la trascendencia es el secreto a voces de la inmanencia].

29 [...] Es braucht strukturmäßig aus sich nicht heraus (sich nicht aus sich selbst herausdrehen), um seine genuinen Tendenzen zur Erfüllung zu bringen. 
segundo a qual a vida tem sua motivação a partir de seu próprio transcurso fático.” (HEIDEGGER, 1993a, p. 31, grifo do autor, tradução nossa).30 Desse modo, é por meio da experiência fática da vida que se realiza o "[...] salto para outro mundo ou, mais exatamente, pela primeira vez no mundo em geral.” (HEIDEGGER, 1999, p. 63, tradução nossa).31

\section{A EXPERIÊNCIA RELIGIOSA: UM MODO DE REALIZAÇÃO DA VIDA FÁTICA}

Chega-se, assim, a um ponto determinante: a experiência fática da vida exige um viver orientado também em direção a um conteúdo, mas que não o antecipa objetivamente e tampouco o preestabelece conceitualmente. "Toda experiência - como experienciar como o que experiencia - pode 'ser assumida no fenômeno'." (HEIDEGGER, 1995, p. 63, grifo do autor, tradução nossa). ${ }^{2}$ Fenômeno é o conteúdo não objetivo da experiência, logo, o experienciado também não é apreendido como processo (Vorgang), mas como acontecimento (Ereignis). Com isso, a relação entre ser-aí e mundo evidencia aquela entre experiência e ser. Como o fenômeno não pode ser apreendido como processo e o ser-aí nunca é isento de perspectivas, o viver como o acontecimento da vida torna possível ver a situação hermenêutica própria ao ser-aí, mostrando o fundamento do qual parte toda interpretação:

1) um ponto de vista [Blickstand], que se fixou e apropriou de modo mais ou menos explícito; 2) uma perspectiva [Blickrichtung], que dele parte, e segundo a qual se determina, preconceptualmente, o ser captado do objeto da interpretação "enquanto tal [coisa]" e "em que direção" deverá ser interpretado; 3) um horizonte [Sichtweite], delimitado pelo ponto de vista e pela perspectiva, dentro do qual a exigência de objetividade da interpretação se move. (HEIDEGGER, 2005, p. 346-347, grifo do autor, tradução nossa). ${ }^{33}$

Isso torna o fenômeno questionável não somente no que diz respeito ao seu conteúdo, mas, sobretudo, ao como (Wie) da relação entre ser-aí e mundo, logo, ao como da realização do sentido. Assim, o “[...] 'viver direcionado para algo interrogativamente' [...]" (HEIDEGGER, 1999, p. 66, tradução nossa),34 é sempre um interrogar intencional-

зо [...] selbstgenügsamkeit ist eine charakterisierte Motivationsrichtung des Lebens an sich und zwar die daß es seine Motivation aus seinem faktischen Ablauf selbst hat.

${ }^{31}[. .$.$] es gelingt der Sprung in eine andere Welt, oder genauer: überhaupt erst in die Welt.$

${ }^{32}$ Jede Erfahrung - als Erfahren wie als Erfahrenes - kann ,ins Phänomen genommen werden.

33 1. ihren mehr oder minder ausdrücklich zugeeigneten und verfestigten Blickstand, 2. eine hieraus motivierte Blickrichtung, in der sich bestimmt das ,als was', in dem der Interpretationsgegenstand vorgrifflich genommen und das ,woraufhin', auf das er ausgelegt werden soll, 3. eine mit Blickstand und Blickrichtung ausgegrenzte Sichtweite, innerhalb deren der jeweilige Objektivitätsanspruch der Interpretation sich bewegt.

$34[\ldots]$,.., fragend Leben auf etwas hin“. 
hermenêutico. A vivência possui uma intencionalidade que já é hermenêutica e que está manifestada na facticidade do ser-aí. A experiência, portanto, desvela a situação hermenêutica própria ao ser-aí, tornando o fenômeno questionável: “[...] 1) pelo ‘que’ [Was] originário, que é experienciado nele (conteúdo) [Gehalt]; 2) pelo 'como' [Wie] originário, em que é experienciado (referência) [Bezug]; 3) pelo ‘como’ [Wie] originário, no qual o sentido referencial é realizado (realização) [Vollzug].” (HEIDEGGER, 1995, p. 63, grifo do autor, tradução nossa).35 Por isso, o conceito de experiência, em Heidegger, assume os contornos de uma indicação formal (formale Anzeige) e não aqueles próprios de uma teoria do conhecimento.

É a partir disso que se olha para a experiência religiosa: o religioso diz respeito ao fenômeno da experiência. Na condição de fenômeno, a religiosidade, como modo de realização da experiência, manifesta o ser-aí em sua facticidade, logo, em sua situação hermenêutica. Com isso, a fenomenologia da religião em Heidegger, de acordo com Vedder, “[...] formalizou a experiência cristã fundamental da vida. Ele não escolhe uma posição a respeito do conteúdo particular dessa experiência, mas limita-se a investigar as condições de sustentação dessa possibilidade.” (VEDDER, 2006, p. 36, tradução nossa). ${ }^{6}$ A indicação formal é o meio necessário para alcançar o significado do que seja experiência religiosa.

O que Heidegger encontra, sobretudo nas cartas paulinas, é uma manifestação originária da vida em sua facticidade. $\mathrm{O}$ cristianismo apresentado nas e pelas cartas paulinas dá a ver uma experiência fundamental da vida em seu aspecto fático e, por isso, mundano, histórico, significativo e apropriativo. A fenomenologia da religião desenvolvida a partir da análise das cartas paulinas propõe um retorno ao âmbito originário da vida, donde a atenção

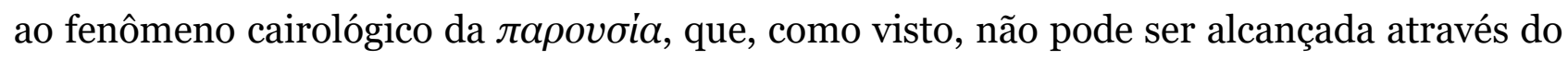
cálculo e, portanto, não é possível falar dele a partir de um domínio cronológico do tempo, mas tão somente da temporalidade cairológica, que, assim, tem a ver com a experiência préteorética, pré subjetivo-objetiva da vida em sua facticidade. Como o conteúdo da experiência nunca pode ser deduzido desde a perspectiva cairológica da $\pi \alpha \rho$ ov $\sigma i \alpha$, a resposta à pergunta pelo quando de sua ocorrência recebe apenas uma indicação, apontando, pois, ao como (Wie) do fenômeno sem objetivá-lo (defini-lo) em um conteúdo, em um que (Was). Por isso,

\footnotetext{
35 [...] 1. nach dein ursprünglichen „Was“, das in ihm erfahren wird (Gehalt), 2. nach dem ursprünglichen „Wie“, in dem es erfahren wird (Bezug), 3. nach dem ursprünglichen „Wie“, in dem der Bezugssinn vollzogen wird (Vollzug).

${ }^{36}[\ldots]$ formalized the fundamental Christian experience of life. He does not choose a position with respect to the particular content of this experience, but rather limits himself to investigating the sustaining conditions of its possibility.
} 
"[...] o decisivo é como eu me comporto com isso na vida autêntica. É disso que surge o sentido do 'quando?', o tempo e o instante." (HEIDEGGER, 1995, p. 99-100, tradução nossa). 37

A compreensão do que seja a experiência religiosa somente indica um como possível de realização da vida em sua facticidade, logo, da expressão experiência religiosa não se deduz nenhuma objetualidade. Antes, ela deve permitir que tal experiência se torne questionável originariamente em seu conteúdo, referência e realização. A indicação formal, no limite, torna possível a compreensão da religiosidade como fenômeno. O que caracteriza a experiência como religiosa, então, não é uma definição conceitual preestabelecida, mas o sentido de conteúdo (Gehaltssinn), de referência (Bezugssinn) e de realização (Vollzugssinn).

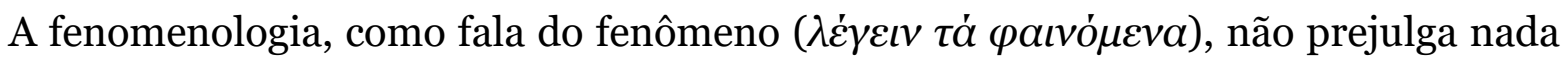
sobre este. Ao falar de experiência religiosa a partir de Heidegger, então, deve-se ter em conta, por um lado, que ela é um conceito formal indicativo que, com vistas a descrever tal fenômeno, parte do como de sua manifestação; por outro, que o sentido advindo é sempre experienciado-manifestado, ou seja, uma concretização da experiência. Não se alcança, com isso, uma determinação prévia do que seja tal religiosidade, pois, para tanto, é necessário que o sentido de conteúdo, de referência e de realização do fenômeno religioso ocorra, ou seja, é necessário que ele, enquanto fenômeno, se concretize de maneira fática. Portanto, a fenomenologia da religião conduzida por Heidegger não pretende a elaboração de um sistema explicativo, pois ela "[...] se coloca numa atitude de ver o fenômeno no seu mesmo mostrar-se, antes que o pensamento raciocinado avente alguma hipótese explicativa, induza ou deduza alguma explicação causal da sua natureza." (ENES, 1971, p. 14).

A indicação formal funciona como a chave metodológica para compreender tanto o significado do que seja experiência religiosa em Heidegger quanto o porquê ela possui um aspecto originário. Ao expor o caráter fático da vida, a indicação formal conceitualiza sem determinar:

A indicação deve indicar antecipando a referência do fenômeno - em um sentido negativo, como se fosse uma advertência! Um fenômeno deve ser dado previamente de tal modo que seu sentido de referência fique em suspenso. Deve-se evitar assumir que o sentido de referência seja originariamente teorético. A referência e a realização do fenômeno não são determinadas antecipadamente, mas estão em suspensão. [...] A indicação formal é uma defesa [Abwehr], um asseguramento [Sicherung] preventivo, de modo que o caráter de

\footnotetext{
37 [...] entscheidend ist, wie ich mich im eigentlichen Leben dazu verhalte. Daraus ergibt sich der Sinn des „Wann?", die Zeit und der Augenblick.
} 
realização [Vollzugscharakter] ainda permaneça livre. (HEIDEGGER, 1995, p. 63-64, grifo do autor, tradução nossa). ${ }^{3}$

A indicação formal inviabiliza a objetivação prévia do fenômeno, deixando-o suspenso no que diz respeito ao seu conteúdo, referência e realização. Os conceitos, compreendidos como indicações formais, “[...] não têm o caráter lógico-formal, nem formaltemático, mas de sinalizações formais. [...] O que é formalmente sinalizado não pode ser tematizado como um todo.” (MACHADO, 2006, p. 43-44). Numa palavra: a indicação formal é um guia que oferece um “[...] primeiro vislumbre de um fenômeno particular [...]” (VEDDER, 2006, p. 45, tradução nossa),39 e, por isso, direciona a necessária ação de atualização da experiência na e a partir da situação hermenêutica. O estar em suspenso da referência e da realização possibilita que o fenômeno seja atualizado justamente por não estar situado objetualmente. Tal suspensão garante a manifestação do fenômeno em sua originariedade, bem como a realização da experiência como experiência de sentido: “[...] as 'indicações formais' [sic], portanto, estariam em conexão com uma versão filosófica capaz de recomeçar constantemente, de voltar a situar-se no começo antes de toda essencialização e universalização.” (HEBECHE, 2005, p. 347). Assim, a possibilidade de manifestação originária do fenômeno religioso está mantida. A fenomenologia da religião, tal como a desenvolve Heidegger, não fornece respostas objetivas à pergunta sobre o que seja o fenômeno religioso, assumindo, ao invés disso, a tarefa de manter aberta tal questão: “[...] a indicação formal renuncia à compreensão última, que só pode ser dada na genuína vivência religiosa.” (HEIDEGGER, 1995, p. 67, tradução nossa).40

Mesmo sendo compreendida como fenômeno, essa religiosidade não deixa de ser experiência de algo, tampouco uma experiência mundana, pois, por um lado, “[...] a experiência fática da vida se situa totalmente no conteúdo, enquanto o como está implícito nisso [...]” (HEIDEGGER, 1995, p. 12, grifo do autor, tradução nossa),41 e, por outro, “[...] mundo é a categoria fundamental do sentido de conteúdo no fenômeno da vida.”

\footnotetext{
${ }_{38}$ Die Anzeige soll vorweg den Bezug des Phänomens anzeigen - in einem negativen Sinn allerdings, gleichsam zur Warnung! Ein Phänomen muß so vorgegeben sein, daß sein Bezugssinn in der Schwebe gehalten wird. Man muß sich davor hüten, anzunehmen, sein Bezugssinn sei ursprünglich der theoretische. Der Bezug und Vollzug des Phänomens wird nicht im Voraus bestimmt, er wird in der Schwebe gehalten. [...] Die formale Anzeige ist eine Abwehr, eine vorhergehende Sicherung, so daß der Vollzugscharakter noch frei bleibt.

39 [...] a first glimpse of a particular phenomenon.

${ }_{40}[. .$.$] Die formale Anzeige verzichtet auf das letzte Verständnis, das nur im genuinen religiösen Erleben$ gegeben werden kann.

${ }_{41}[\ldots .$.$] Die faktische Lebenserfahrung legt sich ganz in den Gehalt, das Wie geht höchstens in diesen mit ein.$
} 
(HEIDEGGER, 1994, p. 86, tradução nossa).42 A fenomenologia heideggeriana da religião se interessa pela experiência religiosa porque esta guarda uma vinculação fundamental com a experiência fática da vida, logo, com a vivência do mundo circundante.

\section{CONSIDERAÇÕES FINAIS}

Alcança-se uma fenomenologia da religião em Heidegger uma vez esclarecido que experiência é uma indicação formal, que religioso é o fenômeno da experiência e que há uma eminente, mas não evidente, vinculação entre vivência (Erlebnis) e experiência (Erfahrung). Como a experiência religiosa é uma possibilidade de realização da experiência, ela diz respeito ao ir orientado para algo desde a situação hermenêutica própria a cada seraí na condição que é a sua. Fenomenologia da religião, então, é sinônimo de fenomenologia da experiência religiosa, na e para a qual a vida fática é o âmbito originário por excelência: "[...] ao falar do âmbito originário (Ursprungsgebiet) da vida, Heidegger está afirmando que toda manifestação vital, todo fenômeno, deve ser entendido enquanto provindo desta origem, originando-se de algum modo a partir dela." (LARA, 2014, p. 68-69, tradução nossa).43 A fenomenologia da religião se propõe a uma condução, a “[...] um conduzir que, em lugares decisivos e em geral, entrega o compreender vivo ao si mesmo e à autenticidade de sua compreensão da origem.” (HEIDEGGER, 1993a, p. 150, tradução nossa).44

Como visto acima, a indicação formal inibe a fixação prévia do fenômeno enquanto objetualidade, isto é, não o determina em seu sentido de conteúdo, referência e realização. Por ser indicativo formal, a experiência religiosa é assumida desde a situação hermenêutica própria ao ser-aí. Dessa maneira, a fenomenologia da religião, em Heidegger, está necessariamente vinculada à hermenêutica da facticidade, pois, ao notabilizar a experiência como indicação formal e o religioso como um fenômeno, mostrou-se também a situação hermenêutica como ponto de partida da investigação fenomenológica. A hermenêutica da facticidade, assim, é fundamentalmente fenomenológica. No limite, então, a fenomenologia da religião proposta por Heidegger nada determina sobre o conteúdo religioso e, no fundo, “[...] seus cursos sobre mística medieval (1919/1920), fenomenologia da religião (1920/1921)

42 [...] Welt ist die Grundkategorie des Gehaltssinnlichen im Phänomen Leben.

43 [...] al hablar de un ámbito del origen (Ursprungsgebiet) de la vida, Heidegger está afirmando que toda manifestación vital, todo fenómeno, debe ser entendido en cuanto surgiendo de dicho origen, originándose de algún modo desde él.

44 [...] Ein Führen, das das lebendige Verstehen in entscheidenden Stellen und überhaupt sich selbst und der Echtheit seines Ursprungsverstehens überläßt. 
e Agostinho (1921) não tinham o propósito final de oferecer uma interpretação da consciência cristã, mas de alcançar uma compreensão clara da tarefa própria da filosofia.” (ESCUDERO, 2011, p. 160, tradução nossa).45 Por isso, essa específica fenomenologia da religião diz respeito a uma dúplice tarefa: por um lado, a de compreender a experiência religiosa e, por outro, a de restabelecer ao ser-aí o âmbito da decisão pela religião como um modo possível de realização da vida em sua facticidade.

\section{REFERÊNCIAS}

1 TESSALONICENSES. In: BÍBLIA DE JERUSALÉM. São Paulo: Paulus, 2002.

CÁCERES, Jorge Espinoza. Dos posibles direcciones de la vivencia interrogativa ¿hay algo? en el joven Heidegger. Transformação, Marília, v. 37, n. 2, p. 219-232, 2014. Disponível em: https://revistas.marilia.unesp.br/index.php/transformacao/article/view/3890.

Acesso em: 04 jun. 2021.

ENES, José. Estrutura coabitacional da vivência religiosa: ensaio de fenomenologia.

Didaskalia, Lisboa, v. 1, n. 1, p. 11-42, 1971. Disponível em:

https://repositorio.ucp.pt/handle/10400.14/5614. Acesso em: 04 jun. 2021.

ESCUDERO, Jesús Adrián. El lenguaje de Heidegger: diccionario filosófico 1912-1927. Barcelona: Herder, 2009.

ESCUDERO, Jesús Adrián. "Sin este origen teológico nunca habría alcanzado el camino del pensar”. El estudiante Heidegger y el sistema del catolicismo. In: XOLOCOTZI, Ángel; GIBU, Ricardo; GODINA, Célida; SANTANDER, J. Rodolfo. La aventura de interpretar: los impulsos filosóficos de Franco Volpi. Ciudad del México: Eón, 2011, p. 157-177.

FERNANDES, Marcos Aurélio. Consciência, vivência e vida: um percurso fenomenológico. Revista da Abordagem Gestáltica, Goiânia, v. 16, n. 1, p. 29-41, 2010. Disponível em: https://biblat.unam.mx/hevila/Revistadaabordagemgestaltica/2010/vol16/no1/4.pdf. Acesso em: 04 jun. 2021.

FLÓREZ, Ramiro. Ser y advenimiento: estancias en el pensamiento de Heidegger. Madrid: Fundación Universitaria Española, 2003.

GÁLATAS. In: BÍBLIA DE JERUSALÉM. São Paulo: Paulus, 2002.

GRIMM, Jacob; GRIMM, Wilhelm. Deutsches Wörterbuch. v. 24. Leipzig: Quellenverzeichnis, 1971.

45 [...] sus cursos sobre mística medieval (1919/20), fenomenología de la religión (1920/21) y Agustín (1921) no tenían el propósito final de ofrecer una interpretación de la conciencia cristiana, sino de lograr una comprensión clara de la tarea propia de la filosofía. 
HEBECHE, Luiz. O escândalo de Cristo: ensaio sobre Heidegger e São Paulo. Ijuí: Unijuí, 2005.

HEIDEGGER, Martin. Sein und Zeit. Tübingen: Max Niemeyer, 1967.

HEIDEGGER, Martin. Die kategorien- und Bedeutungslehre des Duns Scotus. In: HEIDEGGER, Martin. Frühe Schriften (GA 1). Frankfurt am Main: Vittorio Klostermann, 1978, p. 189-412.

HEIDEGGER, Martin. Grundprobleme der Phänomenologie (GA 58). Frankfurt am Main: Vittorio Klostermann, 1993a.

HEIDEGGER, Martin. Phänomenologie der Anschauung und des Ausdrucks: Theorie der philosophischen Begriffsbildung (GA 59). Frankfurt am Main: Vittorio Klostermann, 1993b.

HEIDEGGER, Martin. Phänomenologische Interpretationen zu Aristoteles: Einführung in die phänomenologische Forschung (GA 61). Frankfurt am Main: Vittorio Klostermann, 1994.

HEIDEGGER, Martin. Phänomenologie des religiösen Lebens (GA 60). Frankfurt am Main: Vittorio Klostermann, 1995.

HEIDEGGER, Martin. Die Idee der Philosophie und das Weltanschauungsproblem. In: HEIDEGGER, Martin. Zur Bestimmung der Philosophie (GA 56/57). Frankfurt am Main: Vittorio Klostermann, 1999, p. 3-117.

HEIDEGGER, Martin. O conceito de experiência em Hegel. In: HEIDEGGER, Martin. Caminhos de floresta (GA 5). Tradução Helder Lourenço. Lisboa: Fundação Calouste Gulbenkian, 2002, p. 139-239.

HEIDEGGER, Martin. Phänomenologische Interpretationen ausgewählter Abhandlungen des Aristoteles zur Ontologie und Logik (GA 62). Frankfurt am Main: Vittorio Klostermann, 2005.

HEIDEGGER, Martin. Ontologia: hermenêutica da facticidade (GA 63). Tradução Renato Kirchner. Petrópolis: Vozes, 2013.

LARA, Francisco de. ¿Ciencia originaria o ciencia del origen? Una discusión de la filosofía de Heidegger en sus cursos de 1919 a 1921. Revista de Humanidades, Santiago, n. 30, p. 55-75, 2014. Disponible en: http://revistahumanidades.unab.cl/wpcontent/uploads/2015/o1/Art\%C3\%ADculo-CIENCIA-ORIGINARIA-O-CIENCIAFrancisco-de-Lara-p\%C3\%A1g-55-75.pdf. Acceso en: 04 jun. 2021.

MACHADO, Jorge Antonio Torres. Os indícios de Deus no homem: uma abordagem a partir do método fenomenológico de Martin Heidegger. Porto Alegre: EDIPUCRS, 2006.

PROVINCIATTO, Luís Gabriel. Heidegger, leitor das “Confissões”: a contribuição da autobiografia para sua fenomenologia da religião. Reflexão, Campinas, n. 45, p. 1-11, 2020. Disponível em: 
http://periodicos.puc-campinas.edu.br/seer/index.php/reflexao/article/view/49o8. Acesso em: 04 jun. 2021.

RODRÍGUEZ, Ramón. La transformación hermenéutica de la fenomenología: una interpretación de la obra temprana de Heidegger. San Martín: Unsam Edita, 2019.

SARAMAGO, Ligia. A topologia do ser: lugar, espaço e linguagem no pensamento de Martin Heidegger. São Paulo: Loyola, 2008.

VATTIMO, Gianni. Depois da cristandade: por um cristianismo não religioso. Tradução Cynthia Marques. Rio de Janeiro: Record, 2004.

VEDDER, Ben. Heidegger's philosophy of religion: from God to the Gods.

Pittsburgh: Duquesne University Press, 2006.

Recebido em: 11 fev. 2020 Aprovado em: $06 \mathrm{fev} .2021$ 